OPEN ACCESS

Edited by:

Ivan Dikic,

Goethe Business School, Germany

Reviewed by: Henning Walczak,

Imperial College London, UK Ramin Massoumi

Lund University, Sweden

*Correspondence:

Adan Pinto-Fernandez

adan.pintofernandez@ndm.ox.ac.uk

Specialty section: This article was submitted to Cancer Genetics, a section of the journal

Frontiers in Genetics

Received: 31 March 2016

Accepted: 12 July 2016

Published: 28 July 2016

Citation:

Pinto-Fernandez A and Kessler BM (2016) DUBbing Cancer: Deubiquitylating Enzymes Involved in Epigenetics, DNA Damage and the Cell Cycle As Therapeutic

Targets. Front. Genet. 7:133 doi: 10.3389/fgene.2016.00133

\section{DUBbing Cancer: Deubiquitylating Enzymes Involved in Epigenetics, DNA Damage and the Cell Cycle As Therapeutic Targets}

\author{
Adan Pinto-Fernandez* and Benedikt M. Kessler \\ Target Discovery Institute, Nuffield Department of Medicine, University of Oxford, Oxford, UK
}

Controlling cell proliferation is one of the hallmarks of cancer. A number of critical checkpoints ascertain progression through the different stages of the cell cycle, which can be aborted when perturbed, for instance by errors in DNA replication and repair. These molecular checkpoints are regulated by a number of proteins that need to be present at the right time and quantity. The ubiquitin system has emerged as a central player controlling the fate and function of such molecules such as cyclins, oncogenes and components of the DNA repair machinery. In particular, proteases that cleave ubiquitin chains, referred to as deubiquitylating enzymes (DUBs), have attracted recent attention due to their accessibility to modulation by small molecules. In this review, we describe recent evidence of the critical role of DUBs in aspects of cell cycle checkpoint control, associated DNA repair mechanisms and regulation of transcription, representing pathways altered in cancer. Therefore, DUBs involved in these processes emerge as potentially critical targets for the treatment of not only hematological, but potentially also solid tumors.

\footnotetext{
Keywords: ubiquitin, deubiquitylating enzyme, transcription, epigenetics, DNA damage response, small molecule inhibitors, multiple myeloma, cell cycle checkpoints
}

\section{INTRODUCTION}

Posttranslational modifications dictate the fate and function of most proteins. Chemical modifications by phosphate groups and ubiquitin, a small 76 amino acid protein, are amongst the most common ones. Targeting enzymes that modulate protein phosphorylation, such as protein kinases, has been proven to be a suitable inroad to novel anti-cancer therapeutics. In the case of the ubiquitin system, drug development efforts have been lagging behind due to the complexity of the ubiquitin conjugating and deconjugating mechanisms, and because many aspects of the fundamental biology of this pathway, in particular the topology of poly ubiquitin chains and post-translational modifications present on ubiquitin itself, are not yet fully understood (Cohen and Tcherpakov, 2010; Swatek and Komander, 2016). Despite this, the clinical approval of the proteasome inhibitors Bortezomib, Carfilzomib, and Ixazomib has boosted new drug discovery programs targeting different components of the ubiquitin system (Adams, 2002; Cohen and Tcherpakov, 2010; Ernst et al., 2013; Herndon et al., 2013; Shirley, 2016). 
The ubiquitin system is involved in the regulation of almost every cellular activity through proteolytic and non-proteolytic events, including protein degradation by the $26 \mathrm{~S}$ proteasome or through the lysosomal pathway and autophagy, proteinprotein interactions, protein activity and protein localization (Herndon et al., 2013; Swatek and Komander, 2016). The covalent attachment of ubiquitin to a target protein is catalyzed by the sequential action of three enzymes: E1 activating enzyme, E2 conjugating enzyme and E3 ligase. In the final ubiquitylation step, $\mathrm{Ub}$ is usually transferred to an $\varepsilon-\mathrm{NH}_{2}$ of a lysine residue in the target protein. The addition of one or more ubiquitin monomers to another substrate-attached ubiquitin is possible and leads to formation of polymeric chains. There are different types of $\mathrm{Ub}$ polymers depending on the linkage and on the topology of the chain. The process is reversible and the removal of ubiquitin is catalyzed by a subclass of isopeptidases referred to as deubiquitylating enzymes or DUBs (Hershko and Ciechanover, 1998; Komander and Rape, 2012; Mevissen et al., 2013; Swatek and Komander, 2016).

\section{DEUBIQUITYLATING ENZYMES}

There are $\sim 90$ DUBs encoded in the human genome, which are sub classified into seven different families: ubiquitin-specific proteases (USPs), ubiquitin carboxy-terminal hydrolases (UCHs), ovarian tumor domain con-taining proteases (OTUs), Machado-Joseph disease protein domain proteases (MJD), JAMM/MPN domain-associated metallopeptidases (JAMMs), the monocyte chemo-tactic protein-induced protein (MCPIP) and the motif interacting with Ub-containing novel DUB family (MINDY). Apart from the JAMMs family which has zinc metalloprotease activity, DUBs are cysteine proteases (Komander et al., 2009; Fraile et al., 2012; Kolattukudy and Niu, 2012; Abdul Rehman et al., 2016).

DUB hydrolase activity (predominantly IsoT/USP5) is required to generate free ubiquitin from its precursors because $\mathrm{Ub}$ is transcribed as a fusion of multiple Ub molecules or as a fusion with other proteins (Hadari et al., 1992). Keeping a steady-state level of free Ub is essential for cell viability (Wang C.H. et al., 2014). Therefore, a second process involving DUBs is the recycling of ubiquitin by preventing its degradation, which is mediated by proteasome associated DUBs USP14, $\mathrm{UCH}-\mathrm{L} 5 / \mathrm{UCH} 37$, and POH1, or receptor mediated endocytosis and lysosomal degradation associated DUBs USP8 and AMSH (Reyes-Turcu et al., 2009; Lee et al., 2011). More specifically, DUBs antagonize the action of ubiquitin E3 ligases that target protein substrates for degradation or by regulating E3 ligases activity and/or stability. Generally, the addition of Ub monomers or polymers to a protein can also generate non-proteolytic signals. Thus, DUBs can modulate the outcome of those signals by two main mechanisms: by removing ubiquitin polymers or monomers from proteins involved in these signaling events, but also by editing the linkage and topology of the ubiquitin chains present in the substrate (Komander et al., 2009; Bennett, 2010; Fraile et al., 2012; Komander and Rape, 2012).
Deubiquitylating enzymes activity can be tightly regulated by different means, including transcriptional changes in their gene expressions, microRNAs, post-translational modifications including phosphorylation and auto-ubiquitylation, protein interactions and by changing their subcellular localization (Komander et al., 2009; Fraile et al., 2012; Yang et al., 2012; Wijnhoven et al., 2015). Despite that the number of encoded DUBs is moderate, it is anticipated that most of them act on a discrete set of protein substrates due to restrictions in $\mathrm{Ub}$ chain linkage recognition as observed for OTUs (Mevissen et al., 2013) or metalloprotease DUBs (Komander et al., 2009), or the requirement of interactions with specific adaptors or scaffold proteins, as noted for JAMMs and a subset of USPs (Ventii and Wilkinson, 2008; Komander et al., 2009; Rahighi et al., 2009; Reyes-Turcu et al., 2009; Bremm et al., 2010; Mevissen et al., 2013).

As we will highlight in this review, DUBs emerge as regulators of many cellular signaling pathways critical for cell survival, proliferation, genome stability, and transcriptional control, all of which are important processes that when altered can contribute to the development of neoplasia and tumorigenesis. In particular, ubiquitylation events linked to chromatin-dependent processes appear to involve a large subset of E3 ligases and DUBs that are recognized to be prominent targets in cancer. The possibility of using small molecule inhibitors against DUBs as inroads for anticancer strategies are now receiving a prominent focus in pharma and academia (Nicholson et al., 2007; Sgorbissa et al., 2010; Shi and Grossman, 2010; Edelmann et al., 2011; Fraile et al., 2012; Lim and Baek, 2013; McClurg and Robson, 2015; Lim et al., 2016).

\section{DUBs AFFECTING CHROMATIN FUNCTION}

Histone and other chromatin-associated protein modifications, together with DNA methylation, provide the cell with long-term epigenetic gene transcription regulations without affecting its DNA sequence. Deregulation of these processes is a common event in cancer development and progression (Esteller, 2007; Gronbaek et al., 2007; Segal and Widom, 2009; Simo-Riudalbas and Esteller, 2015). Most histones are post-translationally modified by the addition of different molecules including acetylation, methylation, phosphorylation, SUMOylation, and ubiquitylation. All these histone PTMs (post-translational modifications) play an important role in gene transcription regulation and chromatin remodeling, but also in the DNA damage response (DDR; Weake and Workman, 2008; Zhou et al., 2009; Zhang T. et al., 2015). Consequences of histone ubiquitylation have been extensively reviewed (Weake and Workman, 2008; Belle and Nijnik, 2014). Up to 10\% of cellular histone $\mathrm{H} 2 \mathrm{~A}$ is mono-ubiquitylated on lysine 119 (H2AK119Ub), and this modification is crucial for the regulation of transcription, cell cycle progression, and DDRs (Clague et al., 2015). Polyubiquitylation of the same histone $\mathrm{H} 2 \mathrm{~A}$ (and its variant $\mathrm{H} 2 \mathrm{AX}$ ) on K13/15 is important for the DDR. In the case of Histone $\mathrm{H} 2 \mathrm{~B}, \mathrm{H} 2 \mathrm{BK} 120 \mathrm{Ub}$ has been identified as a marker of gene activation. Other histones are also ubiquitylated, such as histone 
H3, which has an important role in nucleosome assembly. These histone modifications seem to be non-redundant, and whereas ubiquitylation of histone $\mathrm{H} 2 \mathrm{~B}$ is related to transcription activation and silencing, ubiquitylated $\mathrm{H} 2 \mathrm{~A}$ accumulates at repressed promoters. Not surprisingly, a number of DUBs have been identified as histone modifiers (listed in Table 1). Some of these DUBs present specificity for $\mathrm{H} 2 \mathrm{~A}$, others are specific for $\mathrm{H} 2 \mathrm{~B}$, but many of them present dual specificity toward these two histones (see Table 1). The high number of DUBs targeting histones suggests redundant or contextspecific roles for these enzymes (Nakagawa et al., 2008; Feng et al., 2010; Cao and Yan, 2012; Lee et al., 2013; Mosbech et al., 2013; Zhang et al., 2013). The regulation of histones by DUBs has already been linked to cancer. Two good examples are USP22 and BAP1. USP22 deubiquitylates both, H2A and H2B (Zhang et al., 2008a,b; Atanassov et al., 2009; Wang and Dent, 2014). In a recent clinicopathological study in colon carcinoma samples, ubiquitylation of $\mathrm{H} 2 \mathrm{~B}(\mathrm{uH} 2 \mathrm{~B})$ was found to be decreased in colon cancers as compared to normal colon epithelium. Interestingly, high expression levels of USP22 in these tumor samples statistically correlated with reduced levels of uH2B (Wang Z. et al., 2015). USP22 has been linked to poor prognosis in cancer, making it a very attractive target in cancer research. Overexpression of this DUB has been found in colorectal cancer (Liu Y.L. et al., 2011), gastric cancer (Yang et al., 2011; He et al., 2015), liver cancer (Tang et al., 2015a,b), breast cancer (Zhang Y. et al., 2011), glioma (Liang J. et al., 2014), pancreatic cancer ( $\mathrm{He}$ et al., 2015), non-small-cell lung cancer (Hu et al., 2012), salivary adenoid cystic carcinoma (Dai et al., 2014), human pharyngeal squamous cell carcinoma (Dou et al., 2014), and oral squamous cell carcinoma (Piao et al., 2012). BAP1 is a nuclear DUB that targets histone 2A mono-ubiquitylation on lysine 119 (H2AK119ub1; as part of the Polycomb repressor unit; Scheuermann et al., 2010) and regulates histone $\mathrm{H} 3$ lysine methylation and chromatin functions (Dey et al., 2012). The forkhead transcription factor FOXK2 acts a scaffold protein between BAP1 and DNA, promoting targeted epigenetic regulation by BAP1 (Ji et al., 2014; Okino et al., 2015). BAP1 has been identified as a tumor suppressor and as a potential prognostic marker for a number of cancer types. Both, germline and somatic mutations and nuclear expression loss of BAP1 have been linked to increased susceptibility and poor prognosis in malignant melanocytic proliferations (Wiesner et al., 2011; Piris et al., 2015), mesothelioma (Bott et al., 2011), basal cell carcinoma (Mochel et al., 2015), meningioma (Abdel-Rahman et al., 2011), lung cancer (Abdel-Rahman et al., 2011), bladder cancer (Nickerson et al., 2014), thymic carcinoma (Wang Y. et al., 2014), and clear cell renal cell carcinoma (Murali et al., 2013). Although the majority of the published studies suggest that the effects of BAP1 in cancer involve a disruption of the epigenetic homeostasis in these tumors (Wang Y. et al., 2014), for some researchers, it is not so clear that the antitumor effect of BAP1 is only dependent on H2A deubiquitylation (Pena-Llopis et al., 2012).

\section{DUBS ROLE IN THE CROSSTALK BETWEEN THE DIFFERENT HISTONE PTMs}

The crosstalk between different histone PTMs has been described (Zhang T. et al., 2015). JAMM/MPN, a member of the domainassociated metallopeptidases, plays an important role in gene expression regulation by coordinating acetylation of histones with deubiquitylation of histone $\mathrm{H} 2 \mathrm{~A}$ and regulating by this way the association of histone $\mathrm{H} 1$ with nucleosomes (Zhu et al., 2007). USP22 has been found to be associated with the Spt-AdaGcn5-acetyltransferase (SAGA) histone acetyltransferase (HAT) complex. In this context, USP22 deubiquitylates histone H2B and other components of the shelterin complex (Atanassov

TABLE 1 | Selection of deubiquitylating enzymes (DUBs) involved in modulating histone H2A/B ubiquitylation.

\begin{tabular}{|c|c|c|c|}
\hline DUB & Histone (substrate) & Process & Selected reference \\
\hline USP3 & $\mathrm{H} 2 \mathrm{~A}, \gamma \mathrm{H} 2 \mathrm{AX}$ and $\mathrm{H} 2 \mathrm{~B}$ & Cell cycle and DNA double-strand break response & Nicassio et al., 2007 \\
\hline USP7 & $\mathrm{H} 2 \mathrm{~A}$ and $\mathrm{H} 2 \mathrm{~B}$ & Gene expression & van der Knaap et al., 2005; Luo et al., 2015 \\
\hline USP10 & $\mathrm{H} 2 \mathrm{~A}(\mathrm{H} 2 \mathrm{~A} . \mathrm{Z})$ & Transcriptional activation & Draker et al., 2011 \\
\hline USP12 & $\mathrm{H} 2 \mathrm{~A}$ and $\mathrm{H} 2 \mathrm{~B}$ & Xenopus development & Joo et al., 2011 \\
\hline USP16 & $\mathrm{H} 2 \mathrm{~A}$ & Cell cycle and gene expression & Joo et al., 2007; Gu et al., 2016 \\
\hline USP21 & $\mathrm{H} 2 \mathrm{~A}$ & Transcriptional activation & Nakagawa et al., 2008 \\
\hline USP22 & $\mathrm{H} 2 \mathrm{~A}$ and $\mathrm{H} 2 \mathrm{~B}$ & Embryonic development and telomere integrity & $\begin{array}{l}\text { Zhang et al., 2008a,b; Atanassov et al., 2009; } \\
\text { Wang and Dent, } 2014\end{array}$ \\
\hline USP29 & $\mathrm{H} 2 \mathrm{~A}$ and $\mathrm{H} 2 \mathrm{~B}$ & DNA double-strand break response & Mosbech et al., 2013 \\
\hline USP36 & $\mathrm{H} 2 \mathrm{~B}$ & Unknown & Taillebourg et al., 2012 \\
\hline USP44 & $\mathrm{H} 2 \mathrm{~A}$ and $\mathrm{H} 2 \mathrm{~B}$ & DNA double-strand break response $(\mathrm{H} 2 \mathrm{~A})$ and stem cell differentiation ( $\mathrm{H} 2 \mathrm{~B})$ & Fuchs et al., 2012; Mosbech et al., 2013 \\
\hline USP46 & $\mathrm{H} 2 \mathrm{~A}$ and $\mathrm{H} 2 \mathrm{~B}$ & Xenopus development & Joo et al., 2011 \\
\hline USP49 & $\mathrm{H} 2 \mathrm{~B}$ & Co-transcriptional pre-mRNA processing & Zhang et al., 2013 \\
\hline BAP1 & $\mathrm{H} 2 \mathrm{~A}$ & Gene expression & Scheuermann et al., 2010 \\
\hline OTUB1 & Histones (unspecified) & DNA double-strand break response & Sato et al., 2012 \\
\hline BRCC36 & $\mathrm{H} 2 \mathrm{~A}$ and $\gamma \mathrm{H} 2 \mathrm{AX}$ & DNA double-strand break response & Shao et al., 2009 \\
\hline MYSM1 & $\mathrm{H} 2 \mathrm{~A}$ & Gene expression & Zhu et al., 2007; Jiang et al., 2015; Li et al., 2016 \\
\hline
\end{tabular}


et al., 2009). USP17 regulates histone acetylation through deubiquitylation of K63-polyubiquitylated SDS3, inhibiting the histone deacetylase activity (HDAC) of SDS3 and subsequently the proliferation and anchorage-independent growth of tumor cells (Ramakrishna et al., 2011, 2012). A recent study describes that USP7 interacts with and deubiquitylates Tip60, an acetyltransferase targeting histones, resulting in its stabilization (Dar et al., 2013). As mentioned above, BAP1 forms together with ASXL1 the PR-DUB complex that removes ubiquitin from H2AK119Ub. In a recent study, LaFave et al. (2015) found that BAP1 deletion in mice increased the levels of tri-methylated histone $\mathrm{H} 3$ ( $\mathrm{H} 3 \mathrm{~K} 27 \mathrm{me} 3)$ and reduced mono-methylation of the histone $\mathrm{H} 4$ (H4K20me1). A member of the OTU family of DUBs called TRABID (also ZRANB1) was found to be an innate immunological regulator of inflammatory $\mathrm{T}$ cell responses. TRABID regulates histone methylation (H3K9me2, H3K9me3, and $\mathrm{H} 3 \mathrm{~K} 4 \mathrm{me} 3$ ) at the promoter of IL-12 by deubiquitylating and stabilizing the histone demethylase JMJD2D (Jin et al., 2016). In the same study, ectopic expression of TRABID reduced K29, and to a lesser extent K11 ubiquitylation of JMJD2D. This data is consistent with previous published studies describing specificity of this DUB toward K29-linked ubiquitin chains in in vitro assays (Virdee et al., 2010; Licchesi et al., 2012). The protein TIP5 is part of the nucleolar remodeling complex (NoRC) that modulates the silencing of a fraction of rDNA by recruiting histone and DNA methyltransferases. TIP5 is deubiquitylated and stabilized by USP21, resulting in an increase of $\mathrm{H} 3 \mathrm{~K} 4 \mathrm{me} 3$ and rDNA promoter methylation (Khan et al., 2015). It had been previously described that $\mathrm{H} 2 \mathrm{~A}$ ubiquitylation controls the di- and tri-methylation of $\mathrm{H} 3 \mathrm{~K} 4$. In the same study, the authors describe the indirect effects of USP21 on $\mathrm{H} 3 \mathrm{~K} 4 \mathrm{~m} 2$, and $\mathrm{H} 3 \mathrm{~K} 4 \mathrm{~m} 3$ modifications through its H2A histone deubiquitylating activity (Nakagawa et al., 2008). An interesting study has recently linked the roles of the DUB USP7 on epigenetic regulation, cell cycle, and DNA repair (Wang Q. et al., 2016). Upon DNA damage, USP7 interacts, deubiquitylates and stabilizes the histone demethylase PHF8, inducing the specific expression of a subset of genes, including the cell cycle regulator cyclin A2. In the same article, USP7, PHF8, and cyclin A2 were found to be overexpressed in breast carcinomas, correlating with the histological grade of disease. USP24 was also found to target histones by controlling the levels of the histonelysine $N$-methyltransferase Suv39h1, resulting in a modulation of the H3K9me levels. Single-nucleotide polymorphisms (SNPs) of USP24 were found in lung cancer. The variants 930C/T and $7656 \mathrm{~T} / \mathrm{C}$ were increased in tumor samples and were found to induce USP24 expression by stabilizing RNA. (Wang Y.C. et al., 2015). LSD1 (lysine-specific demethylase 1) removes methyl groups from $\mathrm{H} 3 \mathrm{~K} 4$ and also from $\mathrm{H} 3 \mathrm{~K}$ 9. LSD1 has been found to be upregulated in many tumors and its protein levels regulated by the ubiquitin proteasome system. Using a library of siRNA against all human DUBs, USP28 was found as the DUB involved in the stabilization of LSD1. USP28 interacts and deubiquitylates LSD1, and the expression levels of the two proteins correlate well in tumor cell lines and tumor samples (Wu et al., 2013). In conclusion, all these examples are starting to point toward an emerging and important role of the DUBs in the regulation of gene expression by epigenetic events in cancer.

\section{DUBs and DNA METHYLATION}

Only one DUB, USP7, has been described to have a role in the DNA methylation process. USP7 regulates the inheritance of DNA methylation patterns through control of the abundance of Dnmt1, the DNA methyltransferase responsible for this epigenetic mark (Bronner, 2011; Qin et al., 2011). USP7 is part of a protein complex with Dnmt1, the histone acetyl transferase Tip60 and the ubiquitin ligase Uhrf1. USP7 and Urf1 tightly regulate the abundance of Dnmtl in order to control DNA methylation inheritance and replication of methylation patterns. Supporting the role of ubiquitylation in the maintenance of DNA methylation, Nishiyama et al. (2013) have discovered that the ubiquitylation of histone $\mathrm{H} 3$ is necessary to keep the DNA methylation mark by Dnmt1.

\section{DUBs and DNA DAMAGE}

In order to achieve the mutational status that leads to malignancy, tumor cells often deregulate the DDR and the genome maintenance systems (Hanahan and Weinberg, 2011). Under normal physiological conditions, cells have sensor proteins that check for damage in their genome, and once these proteins detect the lesion, repair enzymes are recruited to the damage site to promote repair. Small lesions are repaired by base excision repair (BER), nucleotide excision repair (NER), mismatch repair (MMR) and the Fanconi anemia (FA) pathways. More harmful damages such as double-stranded breaks (DSBs) can be repaired by non-homologous end joining (NHEJ) or through homologous recombination (HR). All the DDR pathways are tightly regulated by PTMs, which includes ubiquitylation/deubiquitylation events. Therefore, DUBs are involved in multiple DDR checkpoints in addition to their capability to modulate histone modifications (Table 2 and Figure 1; Bennett and Harper, 2008; Jacq et al., 2013; Liu et al., 2016; Nie and Boddy, 2016). FA complementation group D2 protein (FANCD2) and proliferating cell nuclear (PCNA), when mono-ubiquitylated, induce the DDR. USP1 targets FANCD2, FANC1, and PCNA for deubiquitylation. FANCD2 and FANC1 are implicated in the FA pathway and PCNA in the translesion synthesis process (Nijman et al., 2005; Oestergaard et al., 2007; Hendel et al., 2011; Villamil et al., 2013; Kim and Kim, 2016). USP1 mutations and deregulated expression levels have been reported in different tumors (GarciaSantisteban et al., 2013). The Chk2-p53-PUMA pathway is another regulator of the DDR generated by double-strand breaks. USP28 was found to stabilize two components of this pathway upon DNA damage, Chk2 and 53BP1 (Zhang et al., 2006). The proteasome-associated DUB Rpn11/POH1 has been described as an important regulator of ubiquitin conjugates generated after DNA damage, thereby representing an important component of the double-strand break response (Butler et al., 2012). BRIT1 is an early DDR factor that is recruited upon DSBs by phosphorylated $\mathrm{H} 2 \mathrm{AX}$ histone $(\gamma-\mathrm{H} 2 \mathrm{AX})$, and it contributes to the final repair process by inducing chromatin relaxation. BRIT1 is deubiquitylated and stabilized by USP8 with the help of the scaffold protein BRUCE, tightly regulating the action 
TABLE 2 | Deubiquitylating enzymes associated with DNA damage responses (DDR).

\begin{tabular}{|c|c|c|c|}
\hline DUB & Non-histone substrate & DDR pathway & Selected reference \\
\hline USP1 & FANCD2, FANCI and PCNA & $\begin{array}{l}\text { Fanconi anemia, post-replication repair (PRR) and } \\
\text { translesion DNA synthesis (TLS) }\end{array}$ & $\begin{array}{l}\text { Nijman et al., 2005; Oestergaard et al., 2007; Hendel et al., } \\
\text { 2011; Villamil et al., 2013; Kim and Kim, } 2016\end{array}$ \\
\hline USP2a & Mdm2 & p53 & Stevenson et al., 2007 \\
\hline USP4 & Auto-deubiquitylation and ARF-BP1 & DSB-response (HR), p53 & Zhang X. et al., 2011; Wijnhoven et al., 2015 \\
\hline USP5 & p53 & p53 & Dayal et al., 2009 \\
\hline USP7 & $\begin{array}{l}\text { Mdm2, p53, Claspin, Chk1, } \\
\text { Ring1b, Bmi1 and RNF168 }\end{array}$ & p53, ATR-Chk1 and $\gamma$-H2AX (DSBs and SSBs) & $\begin{array}{l}\text { Brooks et al., 2007; Faustrup et al., 2009; Brooks and Gu, } \\
\text { 2011; Alonso-de Vega et al., 2014; Qian et al., 2015; Zhu } \\
\text { et al., } 2015\end{array}$ \\
\hline USP8 & BRIT1 & BRIT1-SWI-SNF DSB-response & Ge et al., 2015 \\
\hline USP9X & Claspin & ATR-Chk1 & McGarry et al., 2016 \\
\hline USP10 & p53 and MSH2 & ATM-p53 and mismatch repair (MMR) & Yuan et al., 2010; Zhang et al., 2016 \\
\hline USP11 & p53 & DDR to etoposide & Ke et al., 2014 \\
\hline USP20 & Claspin & ATR-Chk1 & Yuan et al., 2014; Zhu et al., 2014 \\
\hline USP24 & p53 and DDB2 & p53-PUMA & Zhang L. et al., 2012, 2015 \\
\hline USP28 & Chk2 and 53BP1 & Chk2-p53-PUMA & Zhang et al., 2006 \\
\hline USP29 & p53 and Claspin & p53 and ATR-Chk1 & Liu et al., 2011a; Martin et al., 2015 \\
\hline UCH-L5 & NFRKB & DSB-response (HR) & Nishi et al., 2014 \\
\hline OTUB1 & p53 & p53 & Sun et al., 2012 \\
\hline OTUD5 & p53 and PDCD5 & p53 & Luo et al., 2013; Park et al., 2015 \\
\hline Rpn11 & $\begin{array}{l}\text { Ubiquitin conjugates generated by } \\
\text { DNA damage }\end{array}$ & DNA double-strand break response & Butler et al., 2012 \\
\hline
\end{tabular}

of BRIT1 at damaged sites (Ge et al., 2015). USP4 has been found to be important for DSB repair by promoting homologous recombination. USP4 is auto-deubiquitylated on lysine, but potentially also on cysteine residues, and its deubiquitylation is an important step to permit interaction with the DNA-end resection factor CtIP and MRE11-RAD50-NBS1 (MRN) complex, thereby recruiting CtIP to the damaged sites (Wijnhoven et al., 2015). USP10 was recently identified as a partner of MSH2 by mass spectrometry-based interactome studies. MSH2 is an important factor for the mismatch repair pathway and for the resistance to DNA-damaging agents. USP10 stabilizes MSH2, and knockdown of USP10 in lung cancer cells reduces the sensitivity of these cells to DNA damaging agents. A well-known mechanism of DDR involves histone $\mathrm{H} 2 \mathrm{AX}$, which is phosphorylated and accumulated at damaged sites. Then, the ubiquitin ligases RNF168 and RNF8 ubiquitylate $\gamma$-H2AX, thereby inducing the accumulation of repair factors. USP7 has been identified as a regulator of $\gamma-\mathrm{H} 2 \mathrm{AX}$ and $\mathrm{H} 2 \mathrm{~A}$ ubiquitylation by modulating the stability of the E3 ubiquitin ligases RNF168, RINGB1, and BMI1 (Zhu et al., 2015). USP7 is a regulator of different pathways of the DDR, and it is also a modulator of the ATR-Chk1 pathway since it controls the levels of two main components of this response, Chk1 (an essential checkpoint kinase in the DDR) and Claspin (an important component of the ATR-Chk1 axis) (Faustrup et al., 2009; Alonso-de Vega et al., 2014). Other DUBs have also been identified to stabilize Claspin and, therefore, to modulate the ATR-Chk1 pathway, such as is the case for USP9X (McGarry et al., 2016), USP29 (Martin et al., 2015), and USP20 (Yuan et al., 2014; Zhu et al., 2014). In an interesting study, Nishi et al., identified UCH-L5 as the only DUB from a library of 90 DUBs that were able to promote changes in the DDR during three different assays: recruitment at the damaged sites, DDR signaling modulation and DSB repair. The authors found that UCH-L5 interacted with and stabilized NFRKB. NFRKB is a component of the INO80 complex that promotes HR and DNA-end resection (Nishi et al., 2014).

\section{REGULATION OF p53, c-MYC AND OTHER ONCOGENES BY DUBS}

The tumor suppressor p53 is a transcription factor able to control important cellular pathways including DDR, cell cycle, apoptosis, angiogenesis, and senescence. It is called "the guardian of the genome" because of its ability to prevent genome mutation and tumor onset and progression (Nag et al., 2013). p53 levels and subcellular localization are mainly regulated by ubiquitylation (Brooks and $\mathrm{Gu}, 2011$ ). A number of DUBs can modulate p53 signals: USP7 deubiquitylates both p53 and MDM2, one of the ubiquitin ligases that ubiquitylates p53, thereby stabilizing both proteins (Brooks et al., 2007; Brooks and Gu, 2011). Upon DNA damage, USP10 deubiquitylates and activates p53. The same study shows that USP10 suppresses tumor cell growth in cells expressing wild-type p53 (Yuan et al., 2010). USP2a associates with and deubiquitylates MDM2, but not p53, and promotes MDM2-dependent p53 degradation (Stevenson et al., 2007). Overexpression of this DUB was found in different tumors such as glioma (Boustani et al., 2016), bladder cancer (Jeong et al., 2015), prostate cancer (Nelson et al., 2012), and oral squamous carcinoma (da Silva et al., 2009). USP4 interacts with and deubiquitylates another E3 ubiquitin ligase for p53, ARFBP1/Mule/HUWE, leading to the stabilization of ARF-BP1 and subsequent reduction of p53 levels. The same authors found that 


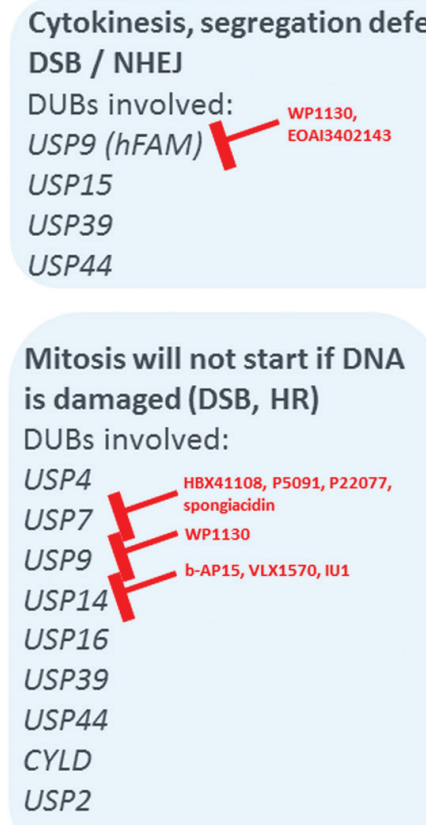

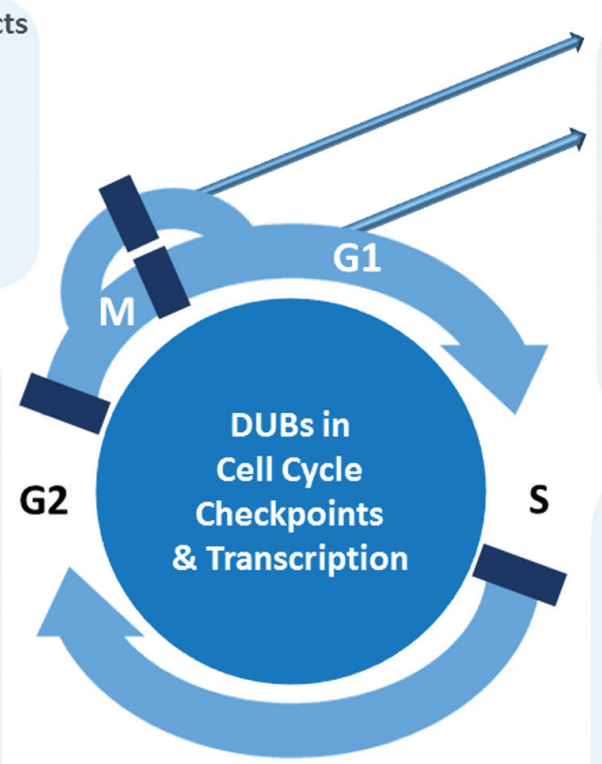

Histone modification

Epigenetic control

Transcription

DUBs involved:

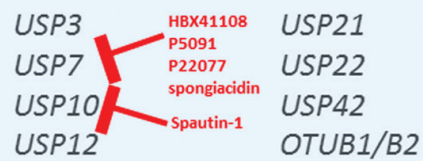

DNA Damage checkpoint

after DNA synthesis (HR, NHEJ)

DUBs involved

$B A P 1$

USP3 HBX41108, P5091, P22077,

USP7

USP1

USP17

USP22

USP28,36,37

USP1/12 MLN323, C527

FIGURE 1 | Deubiquitylating enzymes (DUBs) emerge as major pharmacological targets. Uncontrolled cell proliferation is one of the hallmarks of cancer. Recent literature evidence establishes the critical role of DUBs in aspects of cell cycle checkpoint control, associated DNA repair mechanisms and regulation of transcription, representing pathways altered in cancer. Therefore, DUBs involved in these processes emerge as potentially critical targets for the treatment of not only hematological, but potentially also solid tumors. Small molecule inhibitors available for a subset of DUBs are indicated in red.

USP4 is overexpressed in several types of human cancer, and they suggest that USP4 could be a potential oncogene (Zhang X. et al., 2011; Xing et al., 2016). In response to oxidative stress, USP29 binds to and stabilizes p53. Accumulated p53 quickly induces apoptosis under these conditions (Liu et al., 2011a). OTUB1 is a DUB with preference for substrates with poly ubiquitin K48 linked chains (Mevissen et al., 2013; Altun et al., 2015) that was reported to suppress MDM2-mediated p53 ubiquitylation (Sun et al., 2012). Interestingly, the mechanism by which OTUB1 controls p53 ubiquitylation is independent of its DUB activity. OTUB1 blocks p53 ubiquitylation by MDM2 by interacting with and inhibiting $\mathrm{UbcH} 5$, and $\mathrm{E} 2$ conjugating enzyme for MDM2. Overexpression of OTUB1 in cells drastically stabilizes and activates p53, leading to apoptosis and to a marked inhibition of cell proliferation in a p53-dependent manner (Sun et al., 2012). OTUB1 is also involved in the inhibition of another E2 enzyme, UBC13 (Sato et al., 2012). Since UBC13 is the only $\mathrm{E} 2$ involved in the conjugation of $\mathrm{K} 63 \mathrm{Ub}$ chains, this makes OTUB1 an interesting regulator of both, K63 and K48 polyubiquitin chains signals. OTUB1 is also an activator of a very important oncogene in cancer, RAS. Remarkably, OTUB1 deubiquitylates mono- and di-ubiquitylated RAS, independently of its activation status, resulting in the translocation of the RAS protein to the plasma membrane where it is normally activated (Baietti et al., 2016). OTUB1 expression levels are related with poor prognosis and metastasis in colorectal cancer (Zhou et al., 2014), ovarian cancer (Wang Y. et al., 2016), non-small-cell lung carcinomas (Baietti et al., 2016), and it has been linked to resistance to chemotherapy in breast cancer bearing patients (Karunarathna et al., 2016) and prostate cancer cell invasion (Iglesias-Gato et al., 2015). Knock-down of USP5, the only DUB with specificity for unanchored poly ubiquitin, stabilizes p53 as well. The authors propose a model in which p53 is selectively stabilized because the unanchored poly ubiquitin that accumulates after USP5 knockdown is able to compete with ubiquitylated p53 for proteasomal proteolysis (Dayal et al., 2009). Another DUB, OTUD5, interacts and deubiquitylates p53 in response to DNA damage stress (Luo et al., 2013). PDCD5 is an additional factor accumulated upon DNA damage and regulates the p53 pathway. In a two yeast two-hybrid study to identify partners of PDCD5 in the presence of genotoxic stress, OTUD5 was found to interact with and stabilize PDCD, thereby unveiling a dual role for this enzyme in the regulation of the p53 signals (Park et al., 2015). In another two-hybrid study, USP24 was found to interact with and stabilize DDB2 (UV damage binding protein; Zhang L. et al., 2012). Posteriori, the same authors identified an upregulation of USP24 in a number of tumor cell lines. They found also that USP24 deubiquitylates p53, activating the PUMA pathway, a regulator of DNA-damage-induced apoptosis (Zhang L. et al., 2015). Similarly, it was found that 
USP11 deubiquitylates p53 in response to genotoxicity induced by etoposide (Ke et al., 2014). Other DUBs are linked to the turn-over of important tumor suppressors and oncogenes. For instance, oncogenic transformation by the stabilization of the dual specificity (Tyr/Thr) phosphatase Cdc25A appears to be controlled by Dub3/USP17 (Pereg et al., 2010). USP17 knockdown does lead to a cell cycle arrest in G1/S and G2/M, and high levels of USP17 have been observed in lung, colon, esophagus, and cervix tumor biopsies, underpinning its role in cell cycle control (McFarlane et al., 2010). USP7 is abundantly expressed in many cell types and, as mentioned above, it was shown to deubiquitylate MDM2, thereby modulating p53 stability, but it also has other cellular substrates including FOXO4, Claspin and FOXO3 (Nicholson and Suresh Kumar, 2011). Knockdown of USP7 leads to cell cycle arrest in G1 or G2 (Khoronenkova et al., 2012), which is underpinning its role in controlling several aspects of cell division. The JAMMdomain containing DUB BRCC36 stimulates activity of BRCA1, leading to G2/M checkpoint arrest/control (Mallery et al., 2002). In addition to its role in the p53 pathway, USP28 was also shown to stabilize the oncogene c-MYC after DNA damage. The same authors and others found high expression levels of this DUB in colon, lung, glioma, bladder, and breast carcinomas (Popov et al., 2007a,b; Diefenbacher et al., 2014, 2015; Guo et al., 2014; Wang Z. et al., 2016). USP36 and USP37 also control the stability of c-Myc and thereby affect c-Myc oncogene driven cellular proliferation (Zhang et al., 2006; Pan et al., 2015; Sun et al., 2015).

\section{DUBs AFFECTING CELL CYCLE REGULATORS}

The accumulation and turnover of proteins that regulate the cell cycle such as cyclins, CDKs, and checkpoint signaling molecules is highly orchestrated and controlled to ensure the timely progression through the cell cycle. Inappropriate expression of one or more of these proteins is a common feature of virtually all human tumors. A large number of studies have underscored the importance of E3 ubiquitin ligases and the role they play in regulating cell cycle components [reviewed in Li and Jin (2012)]. However, DUBs that counterbalance E3 ligase activity may also be critical in cell cycle progression (Song and Rape, 2008; Fraile et al., 2012). Indeed, DUB function is frequently miss- regulated in cancer, and our knowledge concerning DUB expression and activity during the different phases of the cell cycle is expanding (for a specific review, see Lim et al., 2016). The regulation of chromatin structure and transcription is one of the key mechanisms by which DUBs exert cell cycle control. DUBs involved in DNA damage checkpoints are exerting effects on cell cycle progression, and these include USP1, USP3, USP7, USP10, USP11, USP16, USP21, USP22, USP28, BRCC36, MYSM1, and BAP1 (Jacq et al., 2013; see also section above). Another key cell cycle checkpoint is the one controlling the correct mitotic spindle assembly, and DUBs such as USP44, CYLD, and USP15 were reported to modulate this process. USP44 acts as a tumor suppressor by preventing chromosome segregation errors (Holland and Cleveland, 2012) via deubiquitylation of the anaphase promoting complex (APC) coactivator Cdc20 (Stegmeier et al., 2007a), and USP44 deletion leads to spontaneous tumor formation, preferentially in the lungs (Zhang Y. et al., 2012). USP15 stabilizes newly synthesized REST and rescues its expression at mitotic exit (Faronato et al., 2013). CYLD targets Plk1 and contributes to regulating mitotic entry (Stegmeier et al., 2007b). USP3 modifies chromatin and is required for S-phase progression (Nicassio et al., 2007). USP2a, as mentioned above, has been linked to different types of cancer. In bladder cancer cells, USP2a was found to deubiquitylate and to stabilize the cell cycle regulator, Cyclin A1, controlling proliferation of these cells (Kim et al., 2012). Taken together, $\sim 15$ (out of $\sim 90$ ) DUBs have been directly linked to molecular processes of the cell cycle (Figure 1).

\section{WILL DUB INHIBITION WORK IN CANCER?}

Generally, DUB function is linked to most cellular processes, but in particular appears to cluster around three major pathways that are commonly deregulated in tumorigenesis. These include transcriptional and epigenetic control of gene expression, DDR pathways and cell cycle checkpoint control (Figure 1). These processes are functionally interconnected, for instance DNA repair mechanisms that are part of cell cycle control checkpoints in the transitions from G2 to $S$ and $M$ to cytokinesis. The associated subset of DUBs are therefore attractive drug candidates, although so far small molecule inhibitors for only a few of them have been reported many of them are subject to intense screening activities (for a comprehensive review, see Kemp, 2016) including natural compounds (Tsukamoto, 2016). The most relevant DUBs related to these pathways with existing chemical matter are UCH-L1, USP1, USP7, USP9, USP14, and UCH-37. Inhibitors of the USP1/UAF complex have been reported, such as ML323, developed based on a N-Benzyl-2-phenylpyrimidin scaffold (Liang Q. et al., 2014), and C527 (SJB3-019A; Mistry et al., 2013). Interestingly, ML323 was found to sensitize the non-small lung cancer cell line H596 to cisplatin (Liang Q. et al., 2014). Most efforts so far have been focused on USP7 (HAUSP), because of its effect on the MDM2-p53 axis. Reported inhibitors include Hybrigenix HBX41108/HBX19818, all based on quinazoline core structures (Colland et al., 2009; Reverdy et al., 2012), Progenra P22077/P5091 developed from a phenyl-thio-2-thienyl building block (Altun et al., 2011; Chauhan et al., 2012), but also natural compounds such as spongiacidin (Yamaguchi et al., 2013). Most promisingly, the USP7 inhibitor P5091 was shown to be able to overcome Bortezomib resistance in Multiple Myeloma cells (Chauhan et al., 2012). However, this chemical scaffold has limited pharmacodynamics properties. A different small molecule, WP1130 and its improved derivative EOAI3402143 based on second-generation tyrphostin derivatives [initially identified as Janus-activated kinase (JAK)-signal transducer], appear to inhibit USP9X and USP24 and consequently increased Myeloma tumor cell apoptosis in vitro and in vivo 
(Peterson et al., 2015). USP9X affects chromosome alignment and segregation via ubiquitylation of survivin (Vong et al., 2005), but has potentially other roles including cell sensitization by affecting the stability of MCL-1, BCR-ABL, and ITCH (Schwickart et al., 2010; Kushwaha et al., 2015). Spautin-1, a quinazolinamine derivative, was characterized as a USP10 inhibitor that to some extent also targets USP13 (Liu et al., 2011b). The resemblance of the quinazoline chemical core element to USP7 inhibitors may offer an opportunity to use this scaffold to further develop inhibitors specific for other USPs.

\section{CLINICAL PERSPECTIVE FOR DUB INHIBITORS}

The USP14 inhibitor IU1 and dual inhibitors of USP14/UCHL5 (proteasomal DUBs) such as b-AP15 (D'Arcy et al., 2011), a bis[(4-nitrophenyl)methylene]-piperidinone derivative or its more recently developed analog VLX1570 (Wang X. et al., 2015), show potentially promising effects that could be potentially translated into the clinic. IU1 appears to accelerate degradation of protein aggregates (Lee et al., 2010), and b-AP15 also overcomes Bortezomib resistance in Multiple Myeloma cells (Tian et al., 2014). As a consequence, VLX1570 has now been cleared to enter Phase I/II for the treatment against Multiple Myeloma patients for whom every other drug combination failed (Taylor, 2016). This represents the first DUB inhibitor reaching the clinical phase, and it is expected that within the next one to two years, a number of other DUB inhibitor candidates will follow also

\section{REFERENCES}

Abdel-Rahman, M. H., Pilarski, R., Cebulla, C. M., Massengill, J. B., Christopher, B. N., Boru, G., et al. (2011). Germline BAP1 mutation predisposes to uveal melanoma, lung adenocarcinoma, meningioma, and other cancers. J. Med. Genet. 48, 856-859. doi: 10.1136/jmedgenet-2011-100156

Abdul Rehman, S. A., Kristariyanto, Y. A., Choi, S.-Y., Nkosi, P. J., Weidlich, S., Labib, K., et al. (2016). MINDY-1 is a member of an evolutionarily conserved and structurally distinct new family of deubiquitinating enzymes. Mol. Cell 63, 146-155. doi: 10.1016/j.molcel.2016.05.009

Adams, J. (2002). Development of the proteasome inhibitor PS-341. Oncologist 7, 9-16. doi: 10.1634/theoncologist.7-1-9

Alonso-de Vega, I., Martin, Y., and Smits, V. A. (2014). USP7 controls Chk1 protein stability by direct deubiquitination. Cell Cycle 13, 3921-3926. doi: 10.4161/15384101.2014.973324

Altun, M., Kramer, H. B., Willems, L. I., McDermott, J. L., Leach, C. A., Goldenberg, S. J., et al. (2011). Activity-based chemical proteomics accelerates inhibitor development for deubiquitylating enzymes. Chem. Biol. 18, 1401-1412. doi: 10.1016/j.chembiol.2011.08.018

Altun, M., Walter, T. S., Kramer, H. B., Herr, P., Iphofer, A., Bostrom, J., et al. (2015). The human otubain2-ubiquitin structure provides insights into the cleavage specificity of poly-ubiquitin-linkages. PLOS ONE 10:e0115344. doi: 10.1371/journal.pone.0115344

Atanassov, B. S., Evrard, Y. A., Multani, A. S., Zhang, Z., Tora, L., Devys, D., et al. (2009). Gcn5 and SAGA regulate shelterin protein turnover and telomere maintenance. Mol. Cell 35, 352-364. doi: 10.1016/j.molcel.2009. 06.015

Baietti, M. F., Simicek, M., Abbasi Asbagh, L., Radaelli, E., Lievens, S., Crowther, J., et al. (2016). OTUB1 triggers lung cancer development by inhibiting RAS monoubiquitination. EMBO Mol. Med. 8, 288-303. doi: 10.15252/emmm.201505972 for the potential treatment of solid tumors. For instance, p53 wildtype expressing tumors (e.g., certain colon cancers) may be suitable for USP7/10 inhibitor based treatment strategies. c-Mycdependent tumors (adenocarcinomas and non-small lung, breast, and colon cancer) could potentially respond to USP28, USP36, USP37, all DUBs affecting c-Myc protein turnover. One third of human cancers present mutations in the oncogene RAS or in components of its effector pathways (Matallanas and Crespo, 2010). The recent discovery describing how OTUB1 control RAS activity (Baietti et al., 2016) may lead to the development of OTUB1 inhibitors targeting RAS mutation based cancers such as pancreatic cancer, colon and melanoma. Clearly, DUBs have now reached center stage as cancer targets, and novel inhibitors for this enzyme class will provide the framework for more effective single agent or combination therapies to better treat hematological and solid tumors.

\section{AUTHOR CONTRIBUTIONS}

BK derived the concept and structure of the manuscript and Figure 1, and he wrote parts of the review. AP-F wrote parts of the review, prepared the tables and contributed to proof-reading.

\section{FUNDING}

This work was supported by the John Fell Fund 133/075 and the Wellcome Trust grant $097813 / \mathrm{Z} / 11 / \mathrm{Z}$ awarded to BK.

Belle, J. I., and Nijnik, A. (2014). H2A-DUBbing the mammalian epigenome: expanding frontiers for histone $\mathrm{H} 2 \mathrm{~A}$ deubiquitinating enzymes in cell biology and physiology. Int. J. Biochem. Cell Biol. 50, 161-174. doi: 10.1016/j.biocel.2014.03.004

Bennett, E. J. (2010). Cellular regulation by deubiquitinating enzymes. Nat. Rev. Mol. Cell Biol. Available at: http://www.nature.com/nrm/posters/dubs/index. html

Bennett, E. J., and Harper, J. W. (2008). DNA damage: ubiquitin marks the spot. Nat. Struct. Mol. Biol. 15, 20-22. doi: 10.1038/nsmb0108-20

Bott, M., Brevet, M., Taylor, B. S., Shimizu, S., Ito, T., Wang, L., et al. (2011). The nuclear deubiquitinase BAP1 is commonly inactivated by somatic mutations and 3p21.1 losses in malignant pleural mesothelioma. Nat. Genet. 43, 668-672. doi: $10.1038 / \mathrm{ng} .855$

Boustani, M. R., Khoshnood, R. J., Nikpasand, F., Taleshi, Z., Ahmadi, K., Yahaghi, E., et al. (2016). Overexpression of ubiquitin-specific protease 2a (USP2a) and nuclear factor erythroid 2-related factor 2 (Nrf2) in human gliomas. J. Neurol. Sci. 363, 249-252. doi: 10.1016/j.jns.2016.03.003

Bremm, A., Freund, S. M., and Komander, D. (2010). Lys11-linked ubiquitin chains adopt compact conformations and are preferentially hydrolyzed by the deubiquitinase Cezanne. Nat. Struct. Mol. Biol. 17, 939-947. doi: $10.1038 / \mathrm{nsmb} .1873$

Bronner, C. (2011). Control of DNMT1 abundance in epigenetic inheritance by acetylation, ubiquitylation, and the histone code. Sci. Signal. 4:e3. doi: 10.1126/scisignal.2001764

Brooks, C. L., and Gu, W. (2011). p53 regulation by ubiquitin. FEBS Lett. 585, 2803-2809. doi: 10.1016/j.febslet.2011.05.022

Brooks, C. L., Li, M., Hu, M., Shi, Y., and Gu, W. (2007). The p53-Mdm2-HAUSP complex is involved in p53 stabilization by HAUSP. Oncogene 26, 7262-7266. doi: 10.1038/sj.onc.1210531

Butler, L. R., Densham, R. M., Jia, J., Garvin, A. J., Stone, H. R., Shah, V., et al. (2012). The proteasomal de-ubiquitinating enzyme POH1 promotes 
the double-strand DNA break response. EMBO J. 31, 3918-3934. doi: 10.1038/emboj.2012.232

Cao, J., and Yan, Q. (2012). Histone ubiquitination and deubiquitination in transcription, DNA damage response, and cancer. Front. Oncol. 2:26. doi: $10.3389 /$ fonc. 2012.00026

Chauhan, D., Tian, Z., Nicholson, B., Kumar, K. G., Zhou, B., Carrasco, R., et al. (2012). A small molecule inhibitor of ubiquitin-specific protease-7 induces apoptosis in multiple myeloma cells and overcomes bortezomib resistance. Cancer Cell 22, 345-358. doi: 10.1016/j.ccr.2012.08.007

Clague, M. J., Heride, C., and Urbe, S. (2015). The demographics of the ubiquitin system. Trends Cell Biol. 25, 417-426. doi: 10.1016/j.tcb.2015.03.002

Cohen, P., and Tcherpakov, M. (2010). Will the ubiquitin system furnish as many drug targets as protein kinases? Cell 143, 686-693. doi: 10.1016/j.cell.2010.11.016

Colland, F., Formstecher, E., Jacq, X., Reverdy, C., Planquette, C., Conrath, S., et al. (2009). Small-molecule inhibitor of USP7/HAUSP ubiquitin protease stabilizes and activates p53 in cells. Mol. Cancer Ther. 8, 2286-2295. doi: 10.1158/1535-7163.MCT-09-0097

D’Arcy, P., Brnjic, S., Olofsson, M. H., Fryknas, M., Lindsten, K., De Cesare, M., et al. (2011). Inhibition of proteasome deubiquitinating activity as a new cancer therapy. Nat. Med. 17, 1636-1640. doi: 10.1038/nm.2536

da Silva, S. D., Cunha, I. W., Nishimoto, I. N., Soares, F. A., Carraro, D. M., Kowalski, L. P., et al. (2009). Clinicopathological significance of ubiquitin-specific protease 2a (USP2a), fatty acid synthase (FASN), and ErbB2 expression in oral squamous cell carcinomas. Oral Oncol. 45, e134-e139. doi: 10.1016/j.oraloncology.2009.02.004

Dai, W., Yao, Y., Zhou, Q., and Sun, C. F. (2014). Ubiquitin-specific peptidase 22, a histone deubiquitinating enzyme, is a novel poor prognostic factor for salivary adenoid cystic carcinoma. PLOS ONE 9:e87148. doi: 10.1371/journal.pone.0087148

Dar, A., Shibata, E., and Dutta, A. (2013). Deubiquitination of Tip60 by USP7 determines the activity of the p53-dependent apoptotic pathway. Mol. Cell. Biol. 33, 3309-3320. doi: 10.1128/MCB.00358-13

Dayal, S., Sparks, A., Jacob, J., Allende-Vega, N., Lane, D. P., and Saville, M. K. (2009). Suppression of the deubiquitinating enzyme USP5 causes the accumulation of unanchored polyubiquitin and the activation of p53. J. Biol. Chem. 284, 5030-5041. doi: 10.1074/jbc.M805871200

Dey, A., Seshasayee, D., Noubade, R., French, D. M., Liu, J., Chaurushiya, M. S., et al. (2012). Loss of the tumor suppressor BAP1 causes myeloid transformation. Science 337, 1541-1546. doi: 10.1126/science.1221711

Diefenbacher, M. E., Chakraborty, A., Blake, S. M., Mitter, R., Popov, N., Eilers, M., et al. (2015). Usp28 counteracts Fbw7 in intestinal homeostasis and cancer. Cancer Res. 75, 1181-1186. doi: 10.1158/0008-5472.CAN-14-1726

Diefenbacher, M. E., Popov, N., Blake, S. M., Schulein-Volk, C., Nye, E., Spencer-Dene, B., et al. (2014). The deubiquitinase USP28 controls intestinal homeostasis and promotes colorectal cancer. J. Clin. Invest. 124, 3407-3418. doi: 10.1172/JCI73733

Dou, Y., Lin, J., Shu, H., and Jiang, N. (2014). Role of ubiquitin-specific peptidase 22 in carcinogenesis of human pharyngeal squamous cell carcinoma. Mol. Med. Rep. 10, 2973-2978. doi: 10.3892/mmr.2014.2589

Draker, R., Sarcinella, E., and Cheung, P. (2011). USP10 deubiquitylates the histone variant $\mathrm{H} 2 \mathrm{~A} . \mathrm{Z}$ and both are required for androgen receptormediated gene activation. Nucleic Acids Res. 39, 3529-3542. doi: 10.1093/nar/ gkq1352

Edelmann, M. J., Nicholson, B., and Kessler, B. M. (2011). Pharmacological targets in the ubiquitin system offer new ways of treating cancer, neurodegenerative disorders and infectious diseases. Expert Rev. Mol. Med. 13:e35. doi: $10.1017 /$ S1462399411002031

Ernst, A., Avvakumov, G., Tong, J., Fan, Y., Zhao, Y., Alberts, P., et al. (2013). A strategy for modulation of enzymes in the ubiquitin system. Science 339, 590-595. doi: 10.1126/science. 1230161

Esteller, M. (2007). Cancer epigenomics: DNA methylomes and histonemodification maps. Nat. Rev. Genet. 8, 286-298. doi: 10.1038/nrg2005

Faronato, M., Patel, V., Darling, S., Dearden, L., Clague, M. J., Urbe, S., et al. (2013). The deubiquitylase USP15 stabilizes newly synthesized REST and rescues its expression at mitotic exit. Cell Cycle 12, 1964-1977. doi: 10.4161/cc. 25035
Faustrup, H., Bekker-Jensen, S., Bartek, J., Lukas, J., and Mailand, N. (2009). USP7 counteracts SCFbetaTrCP- but not APCCdh1-mediated proteolysis of Claspin. J. Cell Biol. 184, 13-19. doi: 10.1083/jcb.200807137

Feng, L., Wang, J., and Chen, J. (2010). The Lys63-specific deubiquitinating enzyme BRCC36 is regulated by two scaffold proteins localizing in different subcellular compartments. J. Biol. Chem. 285, 30982-30988. doi: 10.1074/jbc.M110. 135392

Fraile, J. M., Quesada, V., Rodriguez, D., Freije, J. M., and Lopez-Otin, C. (2012). Deubiquitinases in cancer: new functions and therapeutic options. Oncogene 31, 2373-2388. doi: 10.1038/onc.2011.443

Fuchs, G., Shema, E., Vesterman, R., Kotler, E., Wolchinsky, Z., Wilder, S., et al. (2012). RNF20 and USP44 regulate stem cell differentiation by modulating H2B monoubiquitylation. Mol. Cell 46, 662-673. doi: 10.1016/j.molcel.2012.05.023

Garcia-Santisteban, I., Peters, G. J., Giovannetti, E., and Rodriguez, J. A. (2013). USP1 deubiquitinase: cellular functions, regulatory mechanisms and emerging potential as target in cancer therapy. Mol Cancer 12, 91. doi: 10.1186/14764598-12-91

Ge, C., Che, L., Ren, J., Pandita, R. K., Lu, J., Li, K., et al. (2015). BRUCE regulates DNA double-strand break response by promoting USP8 deubiquitination of BRIT1. Proc. Natl. Acad. Sci. U.S.A. 112, E1210-E1219. doi: 10.1073/pnas.1418335112

Gronbaek, K., Hother, C., and Jones, P. A. (2007). Epigenetic changes in cancer. APMIS 115, 1039-1059. doi: 10.1111/j.1600-0463.2007.apm_636.xml.x

Gu, Y., Jones, A. E., Yang, W., Liu, S., Dai, Q., Liu, Y., et al. (2016). The histone H2A deubiquitinase Usp16 regulates hematopoiesis and hematopoietic stem cell function. Proc. Natl. Acad. Sci. U.S.A. 113, E51-E60. doi: 10.1073/pnas.1517041113

Guo, G., Xu, Y., Gong, M., Cao, Y., and An, R. (2014). USP28 is a potential prognostic marker for bladder cancer. Tumour Biol. 35, 4017-4022. doi: 10.1007/s13277-013-1525-1

Hadari, T., Warms, J. V., Rose, I. A., and Hershko, A. (1992). A ubiquitin C-terminal isopeptidase that acts on polyubiquitin chains. Role in protein degradation. J. Biol. Chem. 267, 719-727.

Hanahan, D., and Weinberg, R. A. (2011). Hallmarks of cancer: the next generation. Cell 144, 646-674. doi: 10.1016/j.cell.2011.02.013

He, Y., Jin, Y. J., Zhang, Y. H., Meng, H. X., Zhao, B. S., Jiang, Y., et al. (2015). Ubiquitin-specific peptidase 22 overexpression may promote cancer progression and poor prognosis in human gastric carcinoma. Transl. Res. 165, 407-416. doi: 10.1016/j.trsl.2014.09.005

Hendel, A., Krijger, P. H., Diamant, N., Goren, Z., Langerak, P., Kim, J., et al. (2011). PCNA ubiquitination is important, but not essential for translesion DNA synthesis in mammalian cells. PLoS Genet. 7:e1002262. doi: 10.1371/journal.pgen.1002262

Herndon, T. M., Deisseroth, A., Kaminskas, E., Kane, R. C., Koti, K. M., Rothmann, M. D., et al. (2013). U.s. Food and Drug Administration approval: carfilzomib for the treatment of multiple myeloma. Clin. Cancer Res. 19, 4559-4563. doi: 10.1158/1078-0432.CCR-13-0755

Hershko, A., and Ciechanover, A. (1998). The ubiquitin system. Annu. Rev. Biochem. 67, 425-479. doi: 10.1146/annurev.biochem.67.1.425

Holland, A. J., and Cleveland, D. W. (2012). The deubiquitinase USP44 is a tumor suppressor that protects against chromosome missegregation. J. Clin. Invest. 122, 4325-4328. doi: 10.1172/JCI66420

Hu, J., Liu, Y. L., Piao, S. L., Yang, D. D., Yang, Y. M., and Cai, L. (2012). Expression patterns of USP22 and potential targets BMI-1, PTEN, p-AKT in non-small-cell lung cancer. Lung Cancer 77, 593-599. doi: 10.1016/j.lungcan.2012.05.112

Iglesias-Gato, D., Chuan, Y. C., Jiang, N., Svensson, C., Bao, J., Paul, I., et al. (2015). OTUB1 de-ubiquitinating enzyme promotes prostate cancer cell invasion in vitro and tumorigenesis in vivo. Mol. Cancer 14, 8. doi: 10.1186/s12943-014$0280-2$

Jacq, X., Kemp, M., Martin, N. M., and Jackson, S. P. (2013). Deubiquitylating enzymes and DNA damage response pathways. Cell Biochem. Biophys. 67, 25-43. doi: 10.1007/s12013-013-9635-3

Jeong, P., Ha, Y. S., Yun, S. J., Yoon, H. Y., Freeman, M. R., Kim, J., et al. (2015). Assess the expression of ubiquitin specific protease USP2a for bladder cancer diagnosis. BMC Urol. 15:80. doi: 10.1186/s12894-015-0074-x

Ji, Z., Mohammed, H., Webber, A., Ridsdale, J., Han, N., Carroll, J. S., et al. (2014). The forkhead transcription factor FOXK2 acts as a chromatin targeting factor 
for the BAP1-containing histone deubiquitinase complex. Nucleic Acids Res. 42, 6232-6242. doi: 10.1093/nar/gku274

Jiang, X. X., Chou, Y., Jones, L., Wang, T., Sanchez, S., Huang, X. F., et al. (2015). Epigenetic regulation of antibody responses by the histone $\mathrm{H} 2 \mathrm{~A}$ deubiquitinase MYSM1. Sci. Rep. 5, 13755. doi: 10.1038/srep13755

Jin, J., Xie, X., Xiao, Y., Hu, H., Zou, Q., Cheng, X., et al. (2016). Epigenetic regulation of the expression of Il12 and Il23 and autoimmune inflammation by the deubiquitinase Trabid. Nat. Immunol. 17, 259-268. doi: 10.1038/ni.3347

Joo, H. Y., Jones, A., Yang, C., Zhai, L., Smith, A. D. I. V., Zhang, Z., et al. (2011). Regulation of histone H2A and $\mathrm{H} 2 \mathrm{~B}$ deubiquitination and Xenopus development by USP12 and USP46. J. Biol. Chem. 286, 7190-7201. doi: 10.1074/jbc.M110.158311

Joo, H. Y., Zhai, L., Yang, C., Nie, S., Erdjument-Bromage, H., Tempst, P., et al. (2007). Regulation of cell cycle progression and gene expression by H2A deubiquitination. Nature 449, 1068-1072. doi: 10.1038/nature06256

Karunarathna, U., Kongsema, M., Zona, S., Gong, C., Cabrera, E., Gomes, A. R., et al. (2016). OTUB1 inhibits the ubiquitination and degradation of FOXM1 in breast cancer and epirubicin resistance. Oncogene 35, 1433-1444. doi: 10.1038/onc.2015.208

Ke, J. Y., Dai, C. J., Wu, W. L., Gao, J. H., Xia, A. J., Liu, G. P., et al. (2014). USP11 regulates 553 stability by deubiquitinating p53. J. Zhejiang Univ. Sci. B 15, 1032-1038. doi: 10.1631/jzus.B1400180

Kemp, M. (2016). Recent advances in the discovery of deubiquitinating enzyme inhibitors. Prog. Med. Chem. 55, 149-192. doi: 10.1016/bs.pmch.2015.10.002

Khan, A., Giri, S., Wang, Y., Chakraborty, A., Ghosh, A. K., Anantharaman, A., et al. (2015). BEND3 represses rDNA transcription by stabilizing a NoRC component via USP21 deubiquitinase. Proc. Natl. Acad. Sci. U.S.A. 112, 83388343. doi: 10.1073/pnas.1424705112

Khoronenkova, S. V., Dianova, I. I., Ternette, N., Kessler, B. M., Parsons, J. L., and Dianov, G. L. (2012). ATM-dependent downregulation of USP7/HAUSP by PPM1G activates 53 response to DNA damage. Mol. Cell 45, 801-813. doi: 10.1016/j.molcel.2012.01.021

Kim, J., Kim, W. J., Liu, Z., Loda, M., and Freeman, M. R. (2012). The ubiquitinspecific protease USP2a enhances tumor progression by targeting cyclin A1 in bladder cancer. Cell Cycle 11, 1123-1130. doi: 10.4161/cc.11.6.19550

Kim, M., and Kim, J. M. (2016). The role of USP1 autocleavage in DNA interstrand crosslink repair. FEBS Lett. 590, 340-348. doi: 10.1002/1873-3468. 12060

Kolattukudy, P. E., and Niu, J. (2012). Inflammation, endoplasmic reticulum stress, autophagy, and the monocyte chemoattractant protein-1/CCR2 pathway. Circ. Res. 110, 174-189. doi: 10.1161/CIRCRESAHA.111.243212

Komander, D., Clague, M. J., and Urbe, S. (2009). Breaking the chains: structure and function of the deubiquitinases. Nat. Rev. Mol. Cell Biol. 10, 550-563. doi: 10.1038/nrm2731

Komander, D., and Rape, M. (2012). The ubiquitin code. Annu. Rev. Biochem. 81, 203-229. doi: 10.1146/annurev-biochem-060310-170328

Kushwaha, D., O’Leary, C., Cron, K. R., Deraska, P., Zhu, K., D’Andrea, A. D., et al. (2015). USP9X inhibition promotes radiation-induced apoptosis in nonsmall cell lung cancer cells expressing mid-to-high MCL1. Cancer Biol. Ther. 16, 392-401. doi: 10.1080/15384047.2014.1002358

LaFave, L. M., Beguelin, W., Koche, R., Teater, M., Spitzer, B., Chramiec, A., et al. (2015). Loss of BAP1 function leads to EZH2-dependent transformation. Nat. Med. 21, 1344-1349. doi: 10.1038/nm.3947

Lee, B. H., Lee, M. J., Park, S., Oh, D. C., Elsasser, S., Chen, P. C., et al. (2010). Enhancement of proteasome activity by a small-molecule inhibitor of USP14. Nature 467, 179-184. doi: 10.1038/nature09299

Lee, M. J., Lee, B. H., Hanna, J., King, R. W., and Finley, D. (2011). Trimming of ubiquitin chains by proteasome-associated deubiquitinating enzymes. Mol. Cell. Proteomics 10:R110003871. doi: 10.1074/mcp.R110.003871

Lee, S. W., Youn, H., Kim, E. J., and Um, S. J. (2013). Retracted: histone H2B ubquitination regulates retinoic acid signaling through the cooperation of ASXL1 and BAP1. Mol. Cell 51, 200-210. doi: 10.1016/j.molcel.2013.06.005

Li, J. M., and Jin, J. (2012). CRL ubiquitin ligases and DNA damage response. Front. Oncol. 2:29. doi: 10.3389/fonc.2012.00029

Li, P., Yang, Y. M., Sanchez, S., Cui, D. C., Dang, R. J., Wang, X. Y., et al. (2016). Deubiquitinase MYSM1 is essential for normal bone formation and mesenchymal stem cell differentiation. Sci. Rep. 6, 22211. doi: $10.1038 /$ srep22211
Liang, J., Zhang, X., Xie, S., Zhou, X., Shi, Q., Hu, J., et al. (2014). Ubiquitin-specific protease 22: a novel molecular biomarker in glioma prognosis and therapeutics. Med. Oncol. 31, 899. doi: 10.1007/s12032-014-0899-2

Liang, Q., Dexheimer, T. S., Zhang, P., Rosenthal, A. S., Villamil, M. A., You, C., et al. (2014). A selective USP1-UAF1 inhibitor links deubiquitination to DNA damage responses. Nat. Chem. Biol. 10, 298-304. doi: 10.1038/nchembio. 1455

Licchesi, J. D., Mieszczanek, J., Mevissen, T. E., Rutherford, T. J., Akutsu, M., Virdee, S., et al. (2012). An ankyrin-repeat ubiquitin-binding domain determines TRABID's specificity for atypical ubiquitin chains. Nat. Struct. Mol. Biol. 19, 62-71. doi: 10.1038/nsmb.2169

Lim, K. H., and Baek, K. H. (2013). Deubiquitinating enzymes as therapeutic targets in cancer. Curr. Pharm. Des. 19, 4039-4052. doi: $10.2174 / 1381612811319220013$

Lim, K. H., Song, M. H., and Baek, K. H. (2016). Decision for cell fate: deubiquitinating enzymes in cell cycle checkpoint. Cell. Mol. Life Sci. 73, 1439-1455. doi: 10.1007/s00018-015-2129-2

Liu, J., Chung, H. J., Vogt, M., Jin, Y., Malide, D., He, L., et al. (2011a). JTV1 coactivates FBP to induce USP29 transcription and stabilize p53 in response to oxidative stress. EMBO J. 30, 846-858. doi: 10.1038/emboj.2011.11

Liu, J., Xia, H., Kim, M., Xu, L., Li, Y., Zhang, L., et al. (2011b). Beclin1 controls the levels of p53 by regulating the deubiquitination activity of USP10 and USP13. Cell 147, 223-234. doi: 10.1016/j.cell.2011.08.037

Liu, Y., Li, Y., and Lu, X. (2016). Regulators in the DNA damage response. Arch. Biochem. Biophys. 594, 18-25. doi: 10.1016/j.abb.2016.02.018

Liu, Y. L., Yang, Y. M., Xu, H., and Dong, X. S. (2011). Aberrant expression of USP22 is associated with liver metastasis and poor prognosis of colorectal cancer. J. Surg. Oncol. 103, 283-289. doi: 10.1002/jso.21802

Luo, J., Lu, Z., Lu, X., Chen, L., Cao, J., Zhang, S., et al. (2013). OTUD5 regulates p53 stability by deubiquitinating p53. PLOS ONE 8:e77682. doi: 10.1371/journal.pone.0077682

Luo, M., Zhou, J., Leu, N. A., Abreu, C. M., Wang, J., Anguera, M. C., et al. (2015). Polycomb protein SCML2 associates with USP7 and counteracts histone $\mathrm{H} 2 \mathrm{~A}$ ubiquitination in the XY chromatin during male meiosis. PLoS Genet. 11:e1004954. doi: 10.1371/journal.pgen.1004954

Mallery, D. L., Vandenberg, C. J., and Hiom, K. (2002). Activation of the E3 ligase function of the BRCA1/BARD1 complex by polyubiquitin chains. EMBO J. 21, 6755-6762. doi: 10.1093/emboj/cdf691

Martin, Y., Cabrera, E., Amoedo, H., Hernandez-Perez, S., DominguezKelly, R., and Freire, R. (2015). USP29 controls the stability of checkpoint adaptor Claspin by deubiquitination. Oncogene 34, 1058-1063. doi: 10.1038/onc.2014.38

Matallanas, D., and Crespo, P. (2010). New druggable targets in the Ras pathway? Curr. Opin. Mol. Ther. 12, 674-683.

McClurg, U. L., and Robson, C. N. (2015). Deubiquitinating enzymes as oncotargets. Oncotarget 6, 9657-9668. doi: 10.18632/oncotarget.3922

McFarlane, C., Kelvin, A. A., de la Vega, M., Govender, U., Scott, C. J., Burrows, J. F., et al. (2010). The deubiquitinating enzyme USP17 is highly expressed in tumor biopsies, is cell cycle regulated, and is required for G1-S progression. Cancer Res. 70, 3329-3339. doi: 10.1158/0008-5472.CAN-09-4152

McGarry, E., Gaboriau, D., Rainey, M., Restuccia, U., Bachi, A., and Santocanale, C. (2016). The deubiquitinase USP9X maintains DNA replication fork stability and DNA damage checkpoint responses by regulating CLASPIN during S-phase. Cancer Res. 76, 2384-2393. doi: 10.1158/0008-5472.CAN-15-2890

Mevissen, T. E., Hospenthal, M. K., Geurink, P. P., Elliott, P. R., Akutsu, M., Arnaudo, N., et al. (2013). OTU deubiquitinases reveal mechanisms of linkage specificity and enable ubiquitin chain restriction analysis. Cell 154, 169-184. doi: 10.1016/j.cell.2013.05.046

Mistry, H., Hsieh, G., Buhrlage, S. J., Huang, M., Park, E., Cuny, G. D., et al. (2013). Small-molecule inhibitors of USP1 target ID1 degradation in leukemic cells. Mol. Cancer Ther. 12, 2651-2662. doi: 10.1158/1535-7163.MCT-13-0103-T

Mochel, M. C., Piris, A., Nose, V., and Hoang, M. P. (2015). Loss of BAP1 expression in basal cell carcinomas in patients with germline BAP1 mutations. Am. J. Clin. Pathol. 143, 901-904. doi: 10.1309/AJCPG8LFJC0DHDQT

Mosbech, A., Lukas, C., Bekker-Jensen, S., and Mailand, N. (2013). The deubiquitylating enzyme USP44 counteracts the DNA double-strand break response mediated by the RNF8 and RNF168 ubiquitin ligases. J. Biol. Chem. 288, 16579-16587. doi: 10.1074/jbc.M113.459917 
Murali, R., Wiesner, T., and Scolyer, R. A. (2013). Tumours associated with BAP1 mutations. Pathology 45, 116-126. doi: 10.1097/PAT.0b013e32835d0efb

Nag, S., Qin, J., Srivenugopal, K. S., Wang, M., and Zhang, R. (2013). The MDM2-p53 pathway revisited. J. Biomed. Res. 27, 254-271. doi: 10.7555/JBR.27.20130030

Nakagawa, T., Kajitani, T., Togo, S., Masuko, N., Ohdan, H., Hishikawa, Y., et al. (2008). Deubiquitylation of histone H2A activates transcriptional initiation via trans-histone cross-talk with $\mathrm{H} 3 \mathrm{~K} 4$ di- and trimethylation. Genes Dev. 22, 37-49. doi: 10.1101/gad.1609708

Nelson, W. G., De Marzo, M. A., and Yegnasubramanian, S. (2012). USP2a activation of MYC in prostate cancer. Cancer Discov. 2, 206-207. doi: 10.1158/2159-8290.CD-12-0027

Nicassio, F., Corrado, N., Vissers, J. H., Areces, L. B., Bergink, S., Marteijn, J. A., et al. (2007). Human USP3 is a chromatin modifier required for S phase progression and genome stability. Curr. Biol. 17, 1972-1977. doi: 10.1016/j.cub.2007.10.034

Nicholson, B., Marblestone, J. G., Butt, T. R., and Mattern, M. R. (2007). Deubiquitinating enzymes as novel anticancer targets. Future Oncol. 3, 191199. doi: 10.2217/14796694.3.2.191

Nicholson, B., and Suresh Kumar, K. G. (2011). The multifaceted roles of USP7; new therapeutic opportunities. Cell Biochem. Biophys. 60, 61-68. doi: 10.1007/s12013-011-9185-5

Nickerson, M. L., Dancik, G. M., Im, K. M., Edwards, M. G., Turan, S., Brown, J., et al. (2014). Concurrent alterations in TERT, KDM6A, and the BRCA pathway in bladder cancer. Clin. Cancer Res. 20, 4935-4948. doi: 10.1158/10780432.CCR-14-0330

Nie, M., and Boddy, M. N. (2016). Cooperativity of the SUMO and ubiquitin pathways in genome stability. Biomolecules 6, 14. doi: 10.3390/biom6010014

Nijman, S. M., Huang, T. T., Dirac, A. M., Brummelkamp, T. R., Kerkhoven, R. M., D'Andrea, A. D., et al. (2005). The deubiquitinating enzyme USP1 regulates the Fanconi anemia pathway. Mol. Cell 17, 331-339. doi: 10.1016/j.molcel.2005.01.008

Nishi, R., Wijnhoven, P., le Sage, C., Tjeertes, J., Galanty, Y., Forment, J. V., et al. (2014). Systematic characterization of deubiquitylating enzymes for roles in maintaining genome integrity. Nat. Cell Biol. 16, 1016-1026. doi: $10.1038 /$ ncb3028

Nishiyama, A., Yamaguchi, L., Sharif, J., Johmura, Y., Kawamura, T., Nakanishi, K., et al. (2013). Uhrf1-dependent H3K23 ubiquitylation couples maintenance DNA methylation and replication. Nature 502, 249-253. doi: 10.1038/nature12488

Oestergaard, V. H., Langevin, F., Kuiken, H. J., Pace, P., Niedzwiedz, W., Simpson, L. J., et al. (2007). Deubiquitination of FANCD2 is required for DNA crosslink repair. Mol. Cell 28, 798-809. doi: 10.1016/j.molcel.2007.09.020

Okino, Y., Machida, Y., Frankland-Searby, S., and Machida, Y. J. (2015). BRCA1-associated protein 1 (BAP1) deubiquitinase antagonizes the ubiquitinmediated activation of FoxK2 target genes. J. Biol. Chem. 290, 1580-1591. doi: 10.1074/jbc.M114.609834

Pan, J., Deng, Q., Jiang, C., Wang, X., Niu, T., Li, H., et al. (2015). USP37 directly deubiquitinates and stabilizes c-Myc in lung cancer. Oncogene 34, 3957-3967. doi: $10.1038 /$ onc. 2014.327

Park, S. Y., Choi, H. K., Choi, Y., Kwak, S., Choi, K. C., and Yoon, H. G. (2015). Deubiquitinase OTUD5 mediates the sequential activation of PDCD5 and $\mathrm{p} 53$ in response to genotoxic stress. Cancer Lett. 357, 419-427. doi: 10.1016/j.canlet.2014.12.005

Pena-Llopis, S., Vega-Rubin-de-Celis, S., Liao, A., Leng, N., Pavia-Jimenez, A., Wang, S., et al. (2012). BAP1 loss defines a new class of renal cell carcinoma. Nat. Genet. 44, 751-759. doi: 10.1038/ng.2323

Pereg, Y., Liu, B. Y., O’Rourke, K. M., Sagolla, M., Dey, A., Komuves, L., et al. (2010). Ubiquitin hydrolase Dub3 promotes oncogenic transformation by stabilizing Cdc25A. Nat. Cell Biol. 12, 400-406. doi: 10.1038/ncb2041

Peterson, L. F., Sun, H., Liu, Y., Potu, H., Kandarpa, M., Ermann, M., et al. (2015). Targeting deubiquitinase activity with a novel small-molecule inhibitor as therapy for B-cell malignancies. Blood 125, 3588-3597. doi: 10.1182/blood2014-10-605584

Piao, S., Liu, Y., Hu, J., Guo, F., Ma, J., Sun, Y., et al. (2012). USP22 is useful as a novel molecular marker for predicting disease progression and patient prognosis of oral squamous cell carcinoma. PLoS ONE 7:e42540. doi: 10.1371/journal.pone. 0042540
Piris, A., Mihm, M. C. Jr., and Hoang, M. P. (2015). BAP1 and BRAFV600E expression in benign and malignant melanocytic proliferations. Hum. Pathol. 46, 239-245. doi: 10.1016/j.humpath.2014.10.015

Popov, N., Herold, S., Llamazares, M., Schulein, C., and Eilers, M. (2007a). Fbw7 and Usp28 regulate myc protein stability in response to DNA damage. Cell Cycle 6, 2327-2331. doi: 10.4161/cc.6.19.4804

Popov, N., Wanzel, M., Madiredjo, M., Zhang, D., Beijersbergen, R., Bernards, R., et al. (2007b). The ubiquitin-specific protease USP28 is required for MYC stability. Nat. Cell Biol. 9, 765-774. doi: 10.1038/ncb1601

Qian, J., Pentz, K., Zhu, Q., Wang, Q., He, J., Srivastava, A. K., et al. (2015). USP7 modulates UV-induced PCNA monoubiquitination by regulating DNA polymerase eta stability. Oncogene 34, 4791-4796. doi: 10.1038/onc.2014.394

Qin, W., Leonhardt, H., and Spada, F. (2011). Usp7 and Uhrf1 control ubiquitination and stability of the maintenance DNA methyltransferase Dnmt1. J. Cell. Biochem. 112, 439-444. doi: 10.1002/jcb.22998

Rahighi, S., Ikeda, F., Kawasaki, M., Akutsu, M., Suzuki, N., Kato, R., et al. (2009). Specific recognition of linear ubiquitin chains by NEMO is important for NF-kappaB activation. Cell 136, 1098-1109. doi: 10.1016/j.cell.2009.03.007

Ramakrishna, S., Suresh, B., Bae, S. M., Ahn, W. S., Lim, K. H., and Baek, K. H. (2012). Hyaluronan binding motifs of USP17 and SDS3 exhibit anti-tumor activity. PLoS ONE 7:e37772. doi: 10.1371/journal.pone.0037772

Ramakrishna, S., Suresh, B., Lee, E. J., Lee, H. J., Ahn, W. S., and Baek, K. H. (2011). Lys-63-specific deubiquitination of SDS3 by USP17 regulates HDAC activity. J. Biol. Chem. 286, 10505-10514. doi: 10.1074/jbc.M110.162321

Reverdy, C., Conrath, S., Lopez, R., Planquette, C., Atmanene, C., Collura, V., et al. (2012). Discovery of specific inhibitors of human USP7/HAUSP deubiquitinating enzyme. Chem. Biol. 19, 467-477. doi: 10.1016/j.chembiol.2012.02.007

Reyes-Turcu, F. E., Ventii, K. H., and Wilkinson, K. D. (2009). Regulation and cellular roles of ubiquitin-specific deubiquitinating enzymes. Annu. Rev. Biochem. 78, 363-397. doi: 10.1146/annurev.biochem.78.082307.091526

Sato, Y., Yamagata, A., Goto-Ito, S., Kubota, K., Miyamoto, R., Nakada, S., et al. (2012). Molecular basis of Lys-63-linked polyubiquitination inhibition by the interaction between human deubiquitinating enzyme OTUB1 and ubiquitin-conjugating enzyme UBC13. J. Biol. Chem. 287, 25860-25868. doi: 10.1074/jbc.M112.364752

Scheuermann, J. C., de Ayala Alonso, A. G., Oktaba, K., Ly-Hartig, N., McGinty, R. K., Fraterman, S., et al. (2010). Histone H2A deubiquitinase activity of the Polycomb repressive complex PR-DUB. Nature 465, 243-247. doi: 10.1038 /nature08966

Schwickart, M., Huang, X., Lill, J. R., Liu, J., Ferrando, R., French, D. M., et al. (2010). Deubiquitinase USP9X stabilizes MCL1 and promotes tumour cell survival. Nature 463, 103-107. doi: 10.1038/nature08646

Segal, E., and Widom, J. (2009). What controls nucleosome positions? Trends Genet. 25, 335-343. doi: 10.1016/j.tig.2009.06.002

Sgorbissa, A., Potu, H., and Brancolini, C. (2010). Isopeptidases in anticancer therapy: looking for inhibitors. Am. J. Transl. Res. 2, 235-247.

Shao, G., Lilli, D. R., Patterson-Fortin, J., Coleman, K. A., Morrissey, D. E., and Greenberg, R. A. (2009). The Rap80-BRCC36 de-ubiquitinating enzyme complex antagonizes RNF8-Ubc13-dependent ubiquitination events at DNA double strand breaks. Proc. Natl. Acad. Sci. U.S.A. 106, 3166-3171. doi: 10.1073/pnas.0807485106

Shi, D., and Grossman, S. R. (2010). Ubiquitin becomes ubiquitous in cancer: emerging roles of ubiquitin ligases and deubiquitinases in tumorigenesis and as therapeutic targets. Cancer Biol. Ther. 10, 737-747. doi: 10.4161/cbt.10.8.13417

Shirley, M. (2016). Ixazomib: first global approval. Drugs 76, 405-411. doi: 10.1007/s40265-016-0548-5

Simo-Riudalbas, L., and Esteller, M. (2015). Targeting the histone orthography of cancer: drugs for writers, erasers and readers. Br. J. Pharmacol. 172, 2716-2732. doi: $10.1111 / \mathrm{bph} .12844$

Song, L., and Rape, M. (2008). Reverse the curse-the role of deubiquitination in cell cycle control. Curr. Opin. Cell Biol. 20, 156-163. doi: 10.1016/j.ceb.2008.01.012

Stegmeier, F., Rape, M., Draviam, V. M., Nalepa, G., Sowa, M. E., Ang, X. L., et al. (2007a). Anaphase initiation is regulated by antagonistic ubiquitination and deubiquitination activities. Nature 446, 876-881. doi: 10.1038/nature05694

Stegmeier, F., Sowa, M. E., Nalepa, G., Gygi, S. P., Harper, J. W., and Elledge, S. J. (2007b). The tumor suppressor CYLD regulates entry into mitosis. Proc. Natl. Acad. Sci. U.S.A. 104, 8869-8874. doi: 10.1073/pnas.0703268104 
Stevenson, L. F., Sparks, A., Allende-Vega, N., Xirodimas, D. P., Lane, D. P., and Saville, M. K. (2007). The deubiquitinating enzyme USP2a regulates the p53 pathway by targeting Mdm2. EMBO J. 26, 976-986. doi: 10.1038/sj.emboj.7601567

Sun, X. X., Challagundla, K. B., and Dai, M. S. (2012). Positive regulation of p53 stability and activity by the deubiquitinating enzyme Otubain 1. EMBO J. 31, 576-592. doi: 10.1038/emboj.2011.434

Sun, X. X., He, X., Yin, L., Komada, M., Sears, R. C., and Dai, M. S. (2015). The nucleolar ubiquitin-specific protease USP36 deubiquitinates and stabilizes c-Myc. Proc. Natl. Acad. Sci. U.S.A. 112, 3734-3739. doi: 10.1073/pnas.1411713112

Swatek, K. N., and Komander, D. (2016). Ubiquitin modifications. Cell Res. 26, 399-422. doi: 10.1038/cr.2016.39

Taillebourg, E., Gregoire, I., Viargues, P., Jacomin, A. C., Thevenon, D., Faure, M., et al. (2012). The deubiquitinating enzyme USP36 controls selective autophagy activation by ubiquitinated proteins. Autophagy 8, 767-779. doi: 10.4161/auto.19381

Tang, B., Liang, X., Tang, F., Zhang, J., Zeng, S., Jin, S., et al. (2015a). Expression of USP22 and Survivin is an indicator of malignant behavior in hepatocellular carcinoma. Int. J. Oncol. 47, 2208-2216. doi: 10.3892/ijo.2015.3214

Tang, B., Tang, F., Li, B., Yuan, S., Xu, Q., Tomlinson, S., et al. (2015b). High USP22 expression indicates poor prognosis in hepatocellular carcinoma. Oncotarget 6, 12654-12667. doi: 10.18632 /oncotarget. 3705

Taylor, D. (2016). Multiple Myeloma Therapy in 2015: an extraordinary moment in oncology. Am. Health Drug Benefits 9, 1-12.

Tian, Z., D’Arcy, P., Wang, X., Ray, A., Tai, Y. T., Hu, Y., et al. (2014). A novel small molecule inhibitor of deubiquitylating enzyme USP14 and UCHL5 induces apoptosis in multiple myeloma and overcomes bortezomib resistance. Blood 123, 706-716. doi: 10.1182/blood-2013-05-500033

Tsukamoto, S. (2016). Search for inhibitors of the ubiquitin-proteasome system from natural sources for cancer therapy. Chem. Pharm. Bull. (Tokyo) 64, 112-118. doi: 10.1248/cpb.c15-00768

van der Knaap, J. A., Kumar, B. R., Moshkin, Y. M., Langenberg, K., Krijgsveld, J., Heck, A. J., et al. (2005). GMP synthetase stimulates histone H2B deubiquitylation by the epigenetic silencer USP7. Mol. Cell 17, 695-707. doi: 10.1016/j.molcel.2005.02.013

Ventii, K. H., and Wilkinson, K. D. (2008). Protein partners of deubiquitinating enzymes. Biochem. J. 414, 161-175. doi: 10.1042/BJ20080798

Villamil, M. A., Liang, Q., and Zhuang, Z. (2013). The WD40-repeat proteincontaining deubiquitinase complex: catalysis, regulation, and potential for therapeutic intervention. Cell Biochem. Biophys. 67, 111-126. doi 10.1007/s12013-013-9637-1

Virdee, S., Ye, Y., Nguyen, D. P., Komander, D., and Chin, J. W. (2010). Engineered diubiquitin synthesis reveals Lys29-isopeptide specificity of an OTU deubiquitinase. Nat. Chem. Biol. 6, 750-757. doi: 10.1038/nchembio.426

Vong, Q. P., Cao, K., Li, H. Y., Iglesias, P. A., and Zheng, Y. (2005). Chromosome alignment and segregation regulated by ubiquitination of survivin. Science 310, 1499-1504. doi: 10.1126/science.1120160

Wang, C. H., Chen, G. C., and Chien, C. T. (2014). The deubiquitinase Leon/USP5 regulates ubiquitin homeostasis during Drosophila development. Biochem. Biophys. Res. Commun. 452, 369-375. doi: 10.1016/j.bbrc.2014. 08.069

Wang, L., and Dent, S. Y. (2014). Functions of SAGA in development and disease. Epigenomics 6, 329-339. doi: 10.2217/epi.14.22

Wang, Q., Ma, S., Song, N., Li, X., Liu, L., Yang, S., et al. (2016). Stabilization of histone demethylase PHF8 by USP7 promotes breast carcinogenesis. J. Clin. Invest. 126, 2205-2220. doi: 10.1172/JCI85747

Wang, X., D’Arcy, P., Caulfield, T. R., Paulus, A., Chitta, K., Mohanty, C., et al. (2015). Synthesis and evaluation of derivatives of the proteasome deubiquitinase inhibitor b-AP15. Chem. Biol. Drug Des. 86, 1036-1048. doi: $10.1111 /$ cbdd. 12571

Wang, Y., Thomas, A., Lau, C., Rajan, A., Zhu, Y., Killian, J. K., et al. (2014). Mutations of epigenetic regulatory genes are common in thymic carcinomas. Sci. Rep. 4:7336. doi: 10.1038/srep07336

Wang, Y., Zhou, X., Xu, M., Weng, W., Zhang, Q., Yang, Y., et al. (2016). OTUB1-catalyzed deubiquitination of FOXM1 facilitates tumor progression and predicts a poor prognosis in ovarian cancer. Oncotarget doi: 10.18632/oncotarget.9160 [Epub ahead of print].
Wang, Y. C., Wang, S. A., Chen, P. H., Hsu, T. I., Yang, W. B., Chuang, Y. P., et al. (2015). Variants of ubiquitin-specific peptidase 24 play a crucial role in lung cancer malignancy. Oncogene doi: 10.1038/onc.2015.432 [Epub ahead of print].

Wang, Z., Song, Q., Xue, J., Zhao, Y., and Qin, S. (2016). Ubiquitin-specific protease 28 is overexpressed in human glioblastomas and contributes to glioma tumorigenicity by regulating MYC expression. Exp. Biol. Med. (Maywood) 241, 255-264. doi: 10.1177/1535370215595468

Wang, Z., Zhu, L., Guo, T., Wang, Y., and Yang, J. (2015). Decreased H2B monoubiquitination and overexpression of ubiquitin-specific protease enzyme 22 in malignant colon carcinoma. Hum. Pathol. 46, 1006-1014. doi: 10.1016/j.humpath.2015.04.001

Weake, V. M., and Workman, J. L. (2008). Histone ubiquitination: triggering gene activity. Mol. Cell 29, 653-663. doi: 10.1016/j.molcel.2008.02.014

Wiesner, T., Obenauf, A. C., Murali, R., Fried, I., Griewank, K. G., Ulz, P., et al. (2011). Germline mutations in BAP1 predispose to melanocytic tumors. Nat. Genet. 43, 1018-1021. doi: 10.1038/ng.910

Wijnhoven, P., Konietzny, R., Blackford, A. N., Travers, J., Kessler, B. M., Nishi, R., et al. (2015). USP4 auto-deubiquitylation promotes homologous recombination. Mol. Cell 60, 362-373. doi: 10.1016/j.molcel.2015.09.019

Wu, Y., Wang, Y., Yang, X. H., Kang, T., Zhao, Y., Wang, C., et al. (2013). The deubiquitinase USP28 stabilizes LSD1 and confers stem-cell-like traits to breast cancer cells. Cell Rep. 5, 224-236. doi: 10.1016/j.celrep.2013.08.030

Xing, C., Lu, X. X., Guo, P. D., Shen, T., Zhang, S., He, X. S., et al. (2016). Ubiquitinspecific protease 4-mediated deubiquitination and stabilization of PRL-3 is required for potentiating colorectal oncogenesis. Cancer Res. 76, 83-95. doi: 10.1158/0008-5472.CAN-14-3595

Yamaguchi, M., Miyazaki, M., Kodrasov, M. P., Rotinsulu, H., Losung, F., Mangindaan, R. E., et al. (2013). Spongiacidin C, a pyrrole alkaloid from the marine sponge Stylissa massa, functions as a USP7 inhibitor. Bioorg. Med. Chem. Lett. 23, 3884-3886. doi: 10.1016/j.bmcl.2013.04.066

Yang, D. D., Cui, B. B., Sun, L. Y., Zheng, H. Q., Huang, Q., Tong, J. X., et al. (2011). The co-expression of USP22 and BMI-1 may promote cancer progression and predict therapy failure in gastric carcinoma. Cell Biochem. Biophys. 61, 703-710. doi: $10.1007 / \mathrm{s} 12013-011-9229-\mathrm{x}$

Yang, S., Banerjee, S., Freitas, A., Cui, H., Xie, N., Abraham, E., et al. (2012). miR-21 regulates chronic hypoxia-induced pulmonary vascular remodeling. Am. J. Physiol. Lung Cell. Mol. Physiol. 302, L521-L529. doi: 10.1152/ajplung.00316.2011

Yuan, J., Luo, K., Deng, M., Li, Y., Yin, P., Gao, B., et al. (2014). HERC2-USP20 axis regulates DNA damage checkpoint through Claspin. Nucleic Acids Res. 42, 13110-13121. doi: 10.1093/nar/gku1034

Yuan, J., Luo, K., Zhang, L., Cheville, J. C., and Lou, Z. (2010). USP10 regulates p53 localization and stability by deubiquitinating p53. Cell 140, 384-396. doi: 10.1016/j.cell.2009.12.032

Zhang, D., Zaugg, K., Mak, T. W., and Elledge, S. J. (2006). A role for the deubiquitinating enzyme USP28 in control of the DNA-damage response. Cell 126, 529-542. doi: 10.1016/j.cell.2006.06.039

Zhang, L., Lubin, A., Chen, H., Sun, Z., and Gong, F. (2012). The deubiquitinating protein USP24 interacts with DDB2 and regulates DDB2 stability. Cell Cycle 11, 4378-4384. doi: 10.4161/cc.22688

Zhang, L., Nemzow, L., Chen, H., Lubin, A., Rong, X., Sun, Z., et al. (2015). The deubiquitinating enzyme USP24 is a regulator of the UV damage response. Cell Rep. 10, 140-147. doi: 10.1016/j.celrep.2014.12.024

Zhang, M., Hu, C., Tong, D., Xiang, S., Williams, K., Bai, W., et al. (2016). Ubiquitin-specific peptidase 10 (USP10) deubiquitinates and stabilizes MutS homolog 2 (MSH2) to regulate cellular sensitivity to DNA damage. J. Biol. Chem. 291, 10783-10791. doi: 10.1074/jbc.M115.700047

Zhang, T., Cooper, S., and Brockdorff, N. (2015). The interplay of histone modifications - writers that read. EMBO Rep. 16, 1467-1481. doi: 10.15252/embr.201540945

Zhang, X., Berger, F. G., Yang, J., and Lu, X. (2011). USP4 inhibits p53 through deubiquitinating and stabilizing ARF-BP1. EMBO J. 30, 2177-2189. doi: 10.1038/emboj.2011.125

Zhang, X. Y., Pfeiffer, H. K., Thorne, A. W., and McMahon, S. B. (2008a). USP22, an hSAGA subunit and potential cancer stem cell marker, reverses the polycomb-catalyzed ubiquitylation of histone H2A. Cell Cycle 7, 1522-1524. doi: $10.4161 /$ cc.7.11.5962 
Zhang, X. Y., Varthi, M., Sykes, S. M., Phillips, C., Warzecha, C., Zhu, W., et al. (2008b). The putative cancer stem cell marker USP22 is a subunit of the human SAGA complex required for activated transcription and cell-cycle progression. Mol. Cell 29, 102-111. doi: 10.1016/j.molcel.2007.12.015

Zhang, Y., Foreman, O., Wigle, D. A., Kosari, F., Vasmatzis, G., Salisbury, J. L., et al. (2012). USP44 regulates centrosome positioning to prevent aneuploidy and suppress tumorigenesis. J. Clin. Invest. 122, 4362-4374. doi: 10.1172/JCI 63084

Zhang, Y., Yao, L., Zhang, X., Ji, H., Wang, L., Sun, S., et al. (2011). Elevated expression of USP22 in correlation with poor prognosis in patients with invasive breast cancer. J. Cancer Res. Clin. Oncol. 137, 1245-1253. doi: 10.1007/s00432-011-0998-9

Zhang, Z., Jones, A., Joo, H. Y., Zhou, D., Cao, Y., Chen, S., et al. (2013). USP49 deubiquitinates histone $\mathrm{H} 2 \mathrm{~B}$ and regulates cotranscriptional pre-mRNA splicing. Genes Dev. 27, 1581-1595. doi: 10.1101/gad.211037.112

Zhou, W., Wang, X., and Rosenfeld, M. G. (2009). Histone H2A ubiquitination in transcriptional regulation and DNA damage repair. Int. J. Biochem. Cell Biol. 41, 12-15. doi: 10.1016/j.biocel.2008.09.016

Zhou, Y., Wu, J., Fu, X., Du, W., Zhou, L., Meng, X., et al. (2014). OTUB1 promotes metastasis and serves as a marker of poor prognosis in colorectal cancer. Mol. Cancer 13, 258. doi: 10.1186/1476-4598-13-258
Zhu, M., Zhao, H., Liao, J., and Xu, X. (2014). HERC2/USP20 coordinates CHK1 activation by modulating CLASPIN stability. Nucleic Acids Res. 42, 1307413081. doi: $10.1093 / \mathrm{nar} / \mathrm{gku} 978$

Zhu, P., Zhou, W., Wang, J., Puc, J., Ohgi, K. A., Erdjument-Bromage, H., et al. (2007). A histone H2A deubiquitinase complex coordinating histone acetylation and $\mathrm{H} 1$ dissociation in transcriptional regulation. Mol. Cell 27 , 609-621. doi: 10.1016/j.molcel.2007.07.024

Zhu, Q., Sharma, N., He, J., Wani, G., and Wani, A. A. (2015). USP7 deubiquitinase promotes ubiquitin-dependent DNA damage signaling by stabilizing RNF168. Cell Cycle 14, 1413-1425. doi: 10.1080/15384101.2015.100 7785

Conflict of Interest Statement: AP and BK are both associated with Cancer Research Technologies and Forma Therapeutics.

Copyright (c) 2016 Pinto-Fernandez and Kessler. This is an open-access article distributed under the terms of the Creative Commons Attribution License (CC BY). The use, distribution or reproduction in other forums is permitted, provided the original author(s) or licensor are credited and that the original publication in this journal is cited, in accordance with accepted academic practice. No use, distribution or reproduction is permitted which does not comply with these terms. 